\title{
Identification of Candidate Gene based Markers (SNPs) in the ZIP Family Transporter Sequences of Rice (Oryza sativa L.)
}

\author{
Saurabh Pandey*, D. Dayal Doss and H.E. Shashidhar
}

Department of Plant Biotechnology, University of Agricultural Sciences, Bangalore-65, India

*Corresponding author

\begin{abstract}
A B S T R A C T
Iron and Zinc are the key ingredient in human nutrition, soil and crop management. Rice is the major dietary source for the population in India but it is deficient in iron and zinc. An effort was made to quantify the iron and zinc content in brown, white and cooked white rice and to study the effect of nucleotide variations in genes associated with zinc. 14 genotypes were selected and grown in field at UAS, GKVK in RCBD, during Kharif-2014. Quality parameter zinc in brown rice showed negative effect on yield. Highly positively significant correlation was observed for grain yield with number of productive tillers. Literature survey revealed genes belonging to transporter family $O S Z I P$ are involved in transporting zinc. Primers were designed specific to these genes. The primer profile at gel level was monomorphic for all the primers. Sequencing the amplicons of primersOsZIP2-1 and OsZIP7-2 revealed that variations were present in all these amplicons but nucleotide changes at ninth position of OsZIP2-1 were significantly associated with brown rice zinc content and nucleotide changes at 25, 40 and 551 positions of OsZIP7-2 were significantly associated with grain iron content. Although OsZIP2-1 and OsZIP7-2 were monomorphic at gel level nucleotide variations were significantly associated with grain iron and zinc content. The markers identified in this study can be used for improving the grain iron and zinc in rice.
\end{abstract}

Keywords

Candidate gene, SNPs, ZIP Family, Oryza sativa, OsZIP

Article Info

Accepted:

17 December 2018

Available Online:

10 January 2019

\section{Introduction}

Rice (Oryza sativa L.) is a "Global Grain" cultivated widely across the world feeding millions of mankind. It has been reported that rice significantly lack some of the micronutrients such as $\mathrm{Fe}, \mathrm{Zn}, \mathrm{Ca}, \mathrm{Mg}, \mathrm{Cu}, \mathrm{I}$ and Se etc., which are important for human beings for their proper growth and development (Banerjee and Chandel, 2011) especially after polishing. Taking weight percentage into account, in rice $43 \%$ of the total $\mathrm{Zn}, 65 \%$ of the total Fe, and $85 \%, 92 \%$ of the total $\mathrm{K}, \mathrm{Ca}$ and $\mathrm{Mn}$ were removed by the milling process if the hull and bran tissues (embryo + aleurone layer) were thoroughly removed from the endosperm fraction during polishing (Lu et al., 2013).Thus, a rice-based diet is the primary cause of micronutrient malnutrition throughout much of the developing world. Iron, zinc, and vitamin A deficiencies are common in rice consuming regions. These deficiencies account for decreased work productivity, reduced mental 
capacity, stunting, blindness, increased child mortality, and elevated morbidity and mortality in general (Baishya et al., 2015)

Biofortification represents one promising strategy to enhance the availability of vitamins and minerals for people whose diets are dominated by micronutrient-poor staple food crops. It involves the identification of varieties of a crop that naturally contain high densities of certain micronutrients. Plant breeders use these varieties to develop new, productive and 'biofortified' crop lines for farmers to grow, market and consume (Global Panel, 2015). Biofortified crops are being developed or adapted by national agricultural programmes in many low and middle income countries (Harvest Plus 2014).

Enormous increase in the availability of the DNA sequences in the databases has increased the potentiality of identifying SSRs and SNPs (Single Nucleotide Polymorphism) by database mining. SNPs are gaining importance in the field of MAS, fueled by ever-increasing sequence data which is publically available. These databases revealed the abundance of SNPs (Sharma and Chauhan 2008). The availability of huge set of databases and also advanced computational genomic tools has provided an opportunity to analyze any sequence for SSR, SNP loci as well as putative CGs responsible for trait of interest. Further, the ever-emerging bioinformatics tools will help in profiling the expression pattern of these CGs and thus identification of most suitable and selective targets for further manipulations in order to improve that trait (Chandel et al., 2011). Chandel et al., (2011) characterized five QTLs, two for QTLs for Fe and three for $\mathrm{Zn}$ content in rice. They have scanned the selected QTLs, results revealed that these QTLs comprises of BAC/PAC clones. This result leads to the identification of eight CGs which are predicted to be involved in activities of uptake, transport and accumulation of $\mathrm{Fe}$ and $\mathrm{Zn}$ in rice. It is also reported that over expression of single genes, which are earlier reported as CGs for $\mathrm{Fe}$ and $\mathrm{Zn}$ concentration, has increased the $\mathrm{Fe}$ (Johnson et al., 2011) and $\mathrm{Zn}$ (Lee et al., 2009) concentration in rice grains, respectively.

Identifying genomic sequences associated with Zinc and designing molecular markers for possible MAS seems an attractive proposition. Candidate gene (CG) approach (Byrne and Mcmullen, 1996) is an attractive strategy. This approach is based on exploiting the information on the role and functions of a particular coding sequence and hypothesizing a plausible cause-effect relationship between the QTL and a feasible candidate gene mapping nearby (Tuberosa and Salvi, 2007).Sequencing these candidate genes and associating the differences in the nucleotide level with the phenotypic variations would give some novel information.

\section{Materials and Methods}

\section{Plant materials}

The present experiment was conducted ataerobic rice laboratory, Department of Plant Biotechnology, University of Agricultural Sciences, GKVK campus, Bangalore, India during Kharif-2014in order to evaluate the performance of fourteen genotypes of rice for various yield and its component traits.

The genotypes were sown in rows spaced at $30 \mathrm{~cm}$ apart with intra-row spacing of $15 \mathrm{~cm}$ withthree replications each. Fourteen genotypes were selected for the study based on earlier studies of Bekele (2012) using more than 1200 rice accessions. These studies were based on AAS and XRF based analysis of Zn and Fe estimation. The list of the selected genotypes is given in Table 1. 


\section{Isolation of genomic DNA}

DNA extraction from fourteen genotypes was done using $\mathrm{CTAB}$ method from young leaves tissues as per the protocol described by Doyle and Doyle (1990) as below.DNA quality was checked on $0.8 \%$ agarose gel. The genomic DNA was quantified spectrophotometrically both at $260 \mathrm{~nm}$ and $280 \mathrm{~nm}$ wavelength. Normalization of the DNA concentration was done to bring all the DNA concentrations to a relatively equal level $(25 \mathrm{ng} / \mu \mathrm{l})$ by appropriate dilutions for PCR reaction.

Exploring the genes associated with zinc and iron transportation in rice

All the genes reported to be associated with $\mathrm{Zn}$ and $\mathrm{Fe}$ transport in rice have been explored. All the potential genes are enlisted in Table 3.Genomic DNA sequence of all the target genes was downloaded. Primers specific to genes associated with $\mathrm{Zn}$ and $\mathrm{Fe}$ content were designed by using the "pick primer" tool of NCBI in collaboration with Primer3 (Ye et al., 2012).

PCR for candidate markers was performed in a total volume of $20 \mu \mathrm{l}$ containing $1 \mathrm{X}$ PCR buffer (contains $10 \mathrm{mM}$ Tris-HCl, $\mathrm{pH} 8.0$ at $\left.25^{\circ} \mathrm{C}, 50 \mathrm{mM} \mathrm{KCl}, 1.5 \mathrm{mM} \mathrm{MgCl} 2\right), 0.25 \mu \mathrm{M}$ of each forward and reverse primers (Sigma Aldrich, USA), $50 \mathrm{ng}$ rice genomic DNA, 0.5 $\mathrm{mM}$ dNTPs mix and 1.2 units of Taq polymerase (Bangalore Genei, India). Condition for PCR amplification was given in the table 2 .

For checking the genotypic variation among all the genotypes PCR product was run on agarose gel $(3.0 \%)$. Care was taken to prevent mixing of samples between the wells. A voltage of $5 \mathrm{~V} / \mathrm{cm}$ was given for a time period of three hours for separation of PCR fragments. The gel was viewed under UV trans-illuminator and the DNA banding pattern was recorded directly and later with Alpha Innotech gel documentation instrument.

\section{Screening of candidate markers for polymorphism}

A total of 20 candidate gene markers designed based on the strategy described earlier, were screened to discern their amplification profiles. The bands generated by gene specific primers were scored as ' 1 ' for bands of higher size bands, ' 3 ' for lower size and ' 2 ' for those showing both the bands.

\section{Single-marker analysis}

Single-marker analysis was done with the help of student's t-test distribution given by Gosset in 1908.

$\mathrm{t}=\frac{\mathrm{X}_{1}-\mathrm{X}_{2}}{\sqrt{\mathrm{SP}^{2}\left(1 / \mathrm{n}_{1}+1 / \mathrm{n}_{2}\right)}}$

Wherein,

$\mathrm{X}_{1}$ : mean of trait of interest under investigation in individuals of marker class I

$\mathrm{X}_{2}$ : mean of trait of interest under investigation in individuals of marker class II

$\mathrm{SP}^{2}$ : Pooled variance

$\mathrm{n}_{1:} \quad$ number of genotypes in marker class I

$\mathrm{n}_{2:} \quad$ number of genotypes in marker class II

$\mathrm{SP}^{2}=\frac{\mathrm{S}_{1}{ }^{2}\left(\mathrm{n}_{1}-1\right)+\mathrm{S}_{2}{ }^{2}\left(\mathrm{n}_{2}-1\right)}{-\mathrm{n}_{1}+\mathrm{n}_{2}-2}$

Wherein,

$\mathrm{S}_{1}{ }^{2:} \quad$ variance of trait of interest for marker class I

$\mathrm{S}_{2}{ }^{2}: \quad$ variance of trait of interest for marker class II

Calculated t-value was compared with table tvalue at $\left(\mathrm{n}_{1+} \mathrm{n}_{2}-2\right)$ degrees of freedom at $5 \%$ and $1 \%$ of probability. 
Sequencing the amplified products and establishing associations with the phenotype

Sequencing of the amplified product(s) was outsourced to "Indus Biotech Pvt. Limited Bangalore". Sequences obtained were then aligned using 'clustalw' tool http://www.ebi.ac.uk/Tools/msa/clustalw2(Lar kin et al., 2007). All sequences of fourteen genotypes were aligned in this tool to discern the variations existing in the sequences. Jalview tool (Waterhouse et al., 2009) of the clustalw website was used for the identification of the variations present in these sequences. Once the sequences were aligned, change at each base was recorded, statistical analysis was done to establish association(s) if any. Each possible change at any position of the sequence was scored. For sequences having same nucleotide as the consensus sequences was given code "1", any change was scored as 2, 3 or 4 depending upon the nucleotide substituted. In case of deletion at that locus, it was scored as 0. These scores were then used for the analysis using SPSS for associating these variations in the nucleotide level with the phenotypic variation for $\mathrm{Zn}$ and $\mathrm{Fe}$ content in brown rice and white rice.

\section{Results and Discussion}

The list of all the zinc transporters obtained by literature survey is shown in Table 3.Primers specific to the nucleotide sequences of zinc and iron transporters is given in Table 14. The expected product size of the primers designed ranged from 484bp to $1090 \mathrm{bp}$, and annealing temperature from $57.6^{0} \mathrm{C}$ to $72^{0} \mathrm{C}$. All the primers screened for all the genotypes with designed molecular markers. All the 20primers are monomorphic. Monomorphic agarose gel picture is presented in Plate 3, 4 and 5 .

Amplified products of two primers (out of 20 gene specific primers) from fourteen genotypes were send for sequencing. The length of each amplicon varied within each primers. OsZIP 7-2 having 602bp instead of expected size of $484 \mathrm{bp}$ this may be due to insertion of segment. OsZIP 2-1 having 745bp product size instead of expected size of 752 bp.

\section{Identification of the variations in the sequences}

The fourteen sequences of each genotype were subjected to alignment using Clustalw (http://www.ebi.ac.uk/Tools/msa/clustalw2/). The pattern of similarities or dissimilarities, in amplicons and the positions where these occur, was recorded.

All the amplicons were found to have variations at nucleotide level which were less in OsZIP 2-1 (only two). Most of the sequence variation was found in OsZIP7-2 amplicon at nucleotide level.

In case of OsZIP 2-1 there has been changes at 2 positions, at 9 position transversion from $\mathrm{A}$ to $\mathrm{T}$ were found for three genotypes, where transversion from A to $\mathrm{C}$ were found for four genotypes; at 12 position transition from $\mathrm{A}$ to $\mathrm{G}$ for two genotypes, transversion from A to $\mathrm{C}$ for two genotypes and transversion from A to $\mathrm{T}$ for four genotypes were found.

In case of OsZIP 7-2, changes were noticed at 26 positions which were mostly deletions. At positions 464 and 542 deletions were found for T; deletions at 540 and 543 were found for $\mathrm{G} ; 544^{\text {th }}$ position for $\mathrm{A} ; 541^{\text {th }}$ position for $\mathrm{C}$. Deletions as well as change in nucleotides to $\mathrm{T}$ could be seen at $34^{\text {th }}$ position from A and G; $64^{\text {th }}$ position from $\mathrm{G} ; 516^{\text {th }}$ position from $\mathrm{G}$; $545^{\text {th }}$ position from $C$; 553th position from $A$ and $\mathrm{C}$. Changes were also found at 25th positions for $\mathrm{C}$ to $\mathrm{T}, \mathrm{G}$ and $\mathrm{A}$; at 26 for $\mathrm{G}$ to $\mathrm{T}$ and $\mathrm{A}$; at 31 th position for $\mathrm{G}$ to $\mathrm{A}$ and $\mathrm{T}$. More changes were observed at 33rd position for $\mathrm{G}$ 
to $\mathrm{A}$ and $\mathrm{T}$; at 41 th position for $\mathrm{C}$ to $\mathrm{A}$ and $\mathrm{G}$; at $48^{\text {th }}$ position for $\mathrm{C}$ to $\mathrm{G}$; at $488^{\text {th }}$ position from $\mathrm{T}$ to $\mathrm{C}$ and $\mathrm{A}$; at 534 from $\mathrm{G}$ to $\mathrm{C}$ with deletions for $\mathrm{G}$; at $548^{\text {th }}$ from $\mathrm{C}$ to $\mathrm{T}$ with deletions for $\mathrm{C}$ : at $549^{\text {th }}$ position from $\mathrm{C}$ to $\mathrm{G}$ with deletions for $\mathrm{C}$; at $550^{\text {th }}$ position from $\mathrm{A}$ to $\mathrm{G}$ and $\mathrm{C}$ With deletions for $\mathrm{A}$; at 551th position from $\mathrm{C}$ to $\mathrm{G}$ with deletions for $\mathrm{C}$; at 552th position from $\mathrm{G}$ to $\mathrm{C}$ with deletions for $\mathrm{G}$ were observed. Nucleotide variation is presented in table 5 and 6.

Associating the nucleotide variation with phenotypic variation

Both primers which manifested changes in nucleotides for the fourteen genotypes were selected. The analysis of scores in SPSS (Statistical Product and Service Solutions) package revealed the association of these sequence changes with the phenotypes. Results are summarized in Table 6 and table 7.

OsZIP 2-1 showed association with only brown rice Zinc among the selected genotypes. It showed association with Zinc in brown rice at two nucleotide positions 09 and 12 with a phenotypic variance of $83.0 \%$ and $67.5 \%$ in all the respective nucleotide positions.

OsZIP 7-2 showed association with Zinc content in brown rice at nucleotide position 25 with a phenotypic variance of $66.2 \%$, at nucleotide position 26 with a phenotypic variance of $62.7 \%$ and at nucleotide position 31 with a phenotypic variance of $69.7 \%$.

OsZIP 7-2 showed association with Iron content in brown rice at different nucleotide positions with varying phenotyping variation as shown in table 5. Zinc and Iron form the important part of micronutrients used for essential physiological processes of human beings. Zinc and Iron accumulation is under the influence of many genes (Avendano, 2000;
Lu et al., 2008; Zhang et al., 2011). To improve the micronutrient bioavailability these genes which are involved in transportation need to be understood properly. Our focus lies on understanding the molecular mechanism behind regulation of $\mathrm{Zn}$ and $\mathrm{Fe}$ haemostasis network in all elite accessions as its discerning is the major bottle neck for biofortification (Ahmad et al., 2014).

Brown rice, as found in our research(Pandey et al., 2018a, Pandey et al., 2018b, Pandey et $a l$., 2018c) also contained high $\mathrm{Fe}$ and $\mathrm{Zn}$, but only very poor and highly health conscious people prefer to eat it. Majority of people prefer white rice though it is significantly less nutritious as almost $70 \%$ of micronutrients are lost during polishing (Sellapan et al., 2009).

Gene-specific markers usually tend to become monomorphic. Monomorphism is an indication of size similarity and not of the sequence. Sequencing of the products obtained by amplifying the DNA would reveal the minute nucleotide level change which may actually be associated with variation in zinc content. Thus sequencing the amplicons would provide more raw data.

There are many genes belonging to family of OsZIP, OsYSL, OsNramp, OsMTP, OsNAS, and APRT. All the genes in these families need to be explored in depth to obtain a clear idea about how these transporters are working and how the available knowledge can be employed to enhance the zinc and iron content in rice grains. Especially, genes like OsZIP need to study to a greater extent which transports Zinc to endosperm. Enriching endosperm is the main focus of present biofortification programmes all over the globe. Primers designed in the NCBI database were worked but the expected product size was different by about 50-100 bp. This could be because japonica rice sequences were used for 
primer design and amplification was done in indica rice. The genomic variation between the two is well documented. Totally 20 primers were used to screen all the fourteen genotypes. All the primers got amplified and all are monomorphic at the agarose gel level. Even though all primers were monomorphic at the agarose gel as they may manifest sequence differences (Fig. 1).

Table.1 List of the selected genotypes with high and low zinc and iron content

\begin{tabular}{|l|l|}
\hline Sl. No. & Variety name/ Cross \\
\hline $\mathbf{1}$ & AM-27 \\
\hline $\mathbf{2}$ & AM-65 \\
\hline $\mathbf{3}$ & AM-72 \\
\hline $\mathbf{4}$ & AM-158 \\
\hline $\mathbf{5}$ & Black rice \\
\hline $\mathbf{6}$ & BI-33 \\
\hline $\mathbf{7}$ & AM-143 \\
\hline $\mathbf{8}$ & AM-1 \\
\hline $\mathbf{9}$ & Radhunipagal \\
\hline $\mathbf{1 0}$ & BR-2655 \\
\hline $\mathbf{1 1}$ & Karthika \\
\hline $\mathbf{1 2}$ & Subhdra \\
\hline $\mathbf{1 3}$ & Moroberekkan \\
\hline $\mathbf{1 4}$ & TKM-9 \\
\hline
\end{tabular}

Table.2 PCR amplification conditions

\begin{tabular}{|l|l|l|l|l|}
\hline Sl. No. & Step & Temperature $\left({ }^{\mathbf{0}} \mathbf{C}\right)$ & Time \\
\hline $\mathbf{1}$ & Initial denaturation & 94 & $5 \mathrm{~min}$ & \\
\hline $\mathbf{2}$ & Denaturation & 94 & $30 \mathrm{sec}$ & \multirow{2}{*}{35 cycles } \\
\hline $\mathbf{3}$ & Primer annealing & Depends on the primers & $1 \mathrm{~min}$ & \\
\hline $\mathbf{4}$ & Primer extension & 72 & $1 \mathrm{~min}$ & \\
\hline $\mathbf{5}$ & Final extension & 72 & $7 \mathrm{~min}$ & \\
\hline $\mathbf{6}$ & Final hold & 04 & Till removal \\
\hline
\end{tabular}

Table.3 List of some of the Zinc transporters in rice

\begin{tabular}{|l|l|l|l|}
\hline Sl. No. & Transporter & Plant part & Reported by \\
\hline $\mathbf{1}$ & OsZIP1 & Root & Bashir et al., 2012 \\
\hline $\mathbf{2}$ & OsZIP2 & Shoot & Banerjee and Chandel, 2011 \\
\hline $\mathbf{3}$ & OsZIP3 & Root & Bashir et al., 2012 \\
\hline $\mathbf{4}$ & OsZIP4 & Shoot/ Grain & Bashir et al., 2012 \\
\hline $\mathbf{5}$ & OsZIP5 & Shoot/ Grain & Bashir et al., 2012 \\
\hline $\mathbf{6}$ & OsZIP6 & Root/ Shoot/ Flower & Banerjee and Chandel, 2011 \\
\hline $\mathbf{7}$ & OsZIP7 & Grain/ Shoot & Banerjee and Chandel, 2011 \\
\hline $\mathbf{8}$ & OsZIP8 & Root/ Shoot/ Grain & Bashir et al., 2012 \\
\hline
\end{tabular}


Table.4 Candidate gene primers were designed using NCBI and Primer-3 tool

\begin{tabular}{|c|c|c|c|c|c|}
\hline S No. & Genes & Forward primer & Reverse primer & $\begin{array}{l}\text { Annealing } \\
\text { temp. }\end{array}$ & $\begin{array}{l}\text { Expected } \\
\text { product size }\end{array}$ \\
\hline 1 & OsZIP1-1 & CTGGCCCAGAAGTCGATCGAT & GCTTTGTCCTGACCTGAGACACC & 67 & 733 \\
\hline 2 & OsZIP1-2 & GATCGCCATTGGTGTCTCAGG & TCAGTCCCAGATCATGACGACAG & 67 & 978 \\
\hline 3 & OsZIP2_1 & GCAGTTGCAGTGTGGTTACG & CGGGTCAGTCAGTCAAGTCA & 64 & 752 \\
\hline 4 & OsZIP2_2 & ATGTGCCAACCTGAACCTCC & TGTGGGTAAATCACCTGAACGA & 65 & 1000 \\
\hline 5 & OsZIP2_3 & CCCACACATTTACTCCGCACT & CACTGACCTGACACGGAACT & 64 & 931 \\
\hline 6 & OsZIP3_1 & ATTGCCTCCATCTTCTGGTCAAG & CTGTTGCCAGGAAGGCCTATGAGC & 67 & 839 \\
\hline 7 & OsZIP3_2 & TCTGATAATCTGCACTTCAGA & AGCATTGACATCAGTCCAGCACCTA & 67 & 1090 \\
\hline 8 & OsZIP4_1 & CCATGGACGCCATGAGGCAGAG & CCATGGACGCCATGAGGCAGAG & 61 & 777 \\
\hline 9 & OsZIP4_2 & TCAGCCTCACAACTGAACCC & CGCACGCTTTTGCTAATGGA & 72 & 515 \\
\hline 10 & OsZIP4_3 & AAAAGCGTGCGAAAAACGACA & GCCCATATGGCAAGCAGAGA & 72 & 910 \\
\hline 11 & OsZIP4_4 & AGAGCAACCAAGAGCTGCAA & AAAAGGAGACAACGCTGGGG & 63.8 & 485 \\
\hline 12 & OsZIP5_1 & ATGTGCCAACCTGAACCTCC & TGTGGGTAAATCACCTGAACGA & 62 & 1000 \\
\hline 13 & OsZIP5_2 & TACTTTGAGGGGCCCAGTTG & TGGTCACTCACTCATCACGC & 64 & 990 \\
\hline 14 & OsZIP5_3 & CGCTCTTCTTCTCCCTGACG & GACGGGTCAGTCAGTCAAGTC & 67 & 521 \\
\hline 15 & OsZIP6_1 & AGAACCACCAGATATTTCAGTC & TGAATCGCTCATGCCACTGT & 62 & 929 \\
\hline 16 & OsZIP6_2 & GGGAAGTCCTGACTCCCAAA & CCTGAAATATCTGGTGGTTCTTTC & 62 & 513 \\
\hline 17 & OsZIP6_3 & GCAGTAAGGCCTAATCTGGGA & TTGGGATCGTGTTCCACTCG & 62 & 606 \\
\hline 18 & OsZIP7_1 & GTGCTTGCGAGGTGTTTGAT & CGTTCTGCTGAATTTCCTCACC & 57.6 & 965 \\
\hline 19 & OsZIP7_2 & GTGGCGTCATTCTACAACGC & CAGCCATCACCACCTCACAT & 72 & 484 \\
\hline 20 & OsZIP7_3 & TGCAAGCCTTAAGACGAACAT & GCGTTGTAGAATGACGCCAC & 68.9 & 934 \\
\hline
\end{tabular}


Table.5 Single-marker analysis for nucleotide changes in OsZIP7-2 and OsZIP2-1 for Zinc contents in different parts of rice grain

\begin{tabular}{|l|l|l|l|}
\hline Primer position & Zinc conc. In & P value & $\mathbf{R}^{\mathbf{2}}$ value \\
\hline OsZIP 7-2_25 & Brown Rice & 0.03 & 66.2 \\
\hline OsZIP 7-2_26 & Brown Rice & 0.01 & 62.7 \\
\hline OsZIP 7-2_31 & Brown Rice & 0.00 & 69.7 \\
\hline OsZIP 7-2_458 & Brown Rice & 0.03 & 46.2 \\
\hline OsZIP 2-1_9 & Brown Rice & 0.00 & 83.0 \\
\hline OsZIP 2-1_12 & Brown Rice & 0.00 & 67.5 \\
\hline
\end{tabular}

Table.6 Single-marker analysis for nucleotide changes in OsZIP7-2 for Iron contents in different parts of rice grain

\begin{tabular}{|l|l|l|l|}
\hline Primer position & Iron conc. in & P value & $\mathbf{R}^{2}$ value \\
\hline OsZIP7-2 25 & Brown Rice & 0.01 & 70.6 \\
\hline OsZIP7-2 33 & Brown Rice & 0.04 & 43.8 \\
\hline OsZIP7-2 34 & Brown Rice & 0.02 & 60.8 \\
\hline OsZIP7-2 40 & Brown Rice & 0.00 & 62.0 \\
\hline OsZIP7-2 41 & Brown Rice & 0.02 & 49.6 \\
\hline OsZIP7-2 43 & Brown Rice & 0.00 & 58.0 \\
\hline OsZIP7-2 48 & Brown Rice & 0.00 & 49.4 \\
\hline OsZIP7-2 64 & Brown Rice & 0.01 & 53.8 \\
\hline OsZIP7-2 464 & Brown Rice & 0.05 & 27.8 \\
\hline OsZIP7-2 516 & Brown Rice & 0.00 & 57.8 \\
\hline OsZIP7-2 534 & Brown Rice & 0.03 & 47.1 \\
\hline OsZIP7-2 540 & Brown Rice & 0.00 & 53.8 \\
\hline OsZIP7-2 541 & Brown Rice & 0.00 & 53.8 \\
\hline OsZIP7-2 542 & Brown Rice & 0.00 & 53.8 \\
\hline OsZIP7-2 543 & Brown Rice & 0.00 & 53.8 \\
\hline OsZIP7-2 544 & Brown Rice & 0.01 & 38.4 \\
\hline OsZIP7-2 545 & Brown Rice & 0.00 & 58.6 \\
\hline OsZIP7-2 548 & Brown Rice & 0.01 & 55.3 \\
\hline OsZIP7-2 549 & Brown Rice & 0.01 & 53.8 \\
\hline OsZIP7-2 550 & Brown Rice & 0.04 & 54.3 \\
\hline OsZIP7-2 551 & Brown Rice & 0.00 & 62.0 \\
\hline OsZIP7-2 552 & Brown Rice & 0.01 & 55.8 \\
\hline OsZIP7-2 553 & Brown Rice & 0.03 & 56.2 \\
\hline
\end{tabular}


Table.7 Nucleotide variations observed in OsZIP 7- 2

\begin{tabular}{|c|c|c|c|c|c|c|c|c|c|c|c|c|c|c|c|c|c|c|c|c|c|c|c|c|c|c|c|}
\hline \multirow{2}{*}{$\begin{array}{l}\text { Sl. } \\
\text { No. }\end{array}$} & \multirow{2}{*}{$\begin{array}{c}\text { GENO } \\
\text { TYPES }\end{array}$} & & & & \multicolumn{23}{|c|}{ POSITIONS } \\
\hline & & 25 & 26 & 31 & 33 & 34 & 40 & 41 & 43 & 48 & 64 & 464 & 488 & 516 & 534 & 540 & 541 & 542 & 543 & 544 & 545 & 548 & 549 & 550 & 551 & 552 & 553 \\
\hline 1 & AM 27 & $\mathrm{C}$ & $\mathbf{T}$ & $\mathbf{G}$ & $\mathbf{G}$ & $\mathbf{T}$ & $\mathbf{T}$ & C & $\mathbf{T}$ & C & & & $\mathbf{T}$ & $\mathbf{T}$ & & G & $\mathbf{C}$ & $\mathbf{T}$ & G & $\mathbf{A}$ & $\mathbf{T}$ & $\mathrm{C}$ & $\mathrm{C}$ & C & $\mathrm{C}$ & $\mathbf{C}$ & C \\
\hline 2 & AM 65 & $\mathrm{C}$ & $\mathbf{A}$ & $\mathbf{A}$ & $\mathbf{A}$ & $\mathbf{T}$ & $\mathbf{T}$ & $\mathbf{A}$ & $\mathbf{G}$ & $\mathrm{C}$ & $\mathbf{T}$ & & $\mathrm{C}$ & & & & & & & & & & & & & & \\
\hline 4 & AM 158 & $\mathbf{T}$ & $\mathbf{G}$ & $\mathbf{G}$ & G & & $\mathbf{T}$ & C & $\mathbf{T}$ & C & & $\mathbf{T}$ & $\mathbf{T}$ & $\mathbf{T}$ & $\mathbf{G}$ & $\mathbf{G}$ & $\mathbf{C}$ & $\mathbf{T}$ & $\mathbf{G}$ & $\mathbf{A}$ & $\mathrm{C}$ & $\mathrm{C}$ & $\mathbf{C}$ & $\mathbf{C}$ & $\mathbf{C}$ & $\mathbf{G}$ & $\mathbf{T}$ \\
\hline 5 & Black rice & $\mathbf{T}$ & $\mathbf{G}$ & $\mathbf{G}$ & $\mathbf{G}$ & & $\mathbf{T}$ & C & $\mathbf{T}$ & $\mathrm{C}$ & & & $\mathbf{T}$ & $\mathbf{T}$ & & $\mathbf{G}$ & $\mathrm{C}$ & $\mathbf{T}$ & $\mathbf{G}$ & A & $\mathbf{T}$ & $\mathrm{C}$ & $\mathrm{C}$ & A & $\mathbf{G}$ & $\mathbf{G}$ & $\mathbf{T}$ \\
\hline 6 & BI 33 & & G & $\mathbf{G}$ & $\mathbf{G}$ & $\mathbf{A}$ & $\mathbf{T}$ & C & $\mathbf{T}$ & $\mathrm{C}$ & & & $\mathbf{T}$ & $\mathbf{T}$ & $\mathbf{G}$ & $\mathbf{G}$ & $\mathrm{C}$ & $\mathbf{T}$ & $\mathbf{G}$ & $\mathbf{A}$ & $\mathbf{C}$ & $\mathrm{C}$ & $\mathrm{C}$ & $\mathbf{C}$ & $\mathbf{G}$ & $\mathbf{G}$ & $\mathbf{T}$ \\
\hline 7 & AM 143 & $\mathrm{C}$ & G & $\mathbf{G}$ & G & & $\mathbf{T}$ & C & $\mathbf{T}$ & $\mathrm{C}$ & & & $\mathbf{T}$ & $\mathbf{T}$ & & $\mathbf{G}$ & C & $\mathbf{T}$ & $\mathbf{G}$ & $\mathbf{A}$ & $\mathbf{T}$ & $\mathbf{T}$ & G & $\mathbf{A}$ & $\mathrm{C}$ & $\mathbf{G}$ & $\mathbf{T}$ \\
\hline 8 & AM 1 & $\mathrm{C}$ & G & $\mathbf{G}$ & $\mathbf{G}$ & & $\mathbf{T}$ & C & $\mathbf{T}$ & $\mathrm{C}$ & & & $\mathbf{T}$ & $\mathbf{T}$ & $\mathbf{C}$ & $\mathbf{G}$ & C & $\mathbf{T}$ & $\mathbf{G}$ & $\mathbf{A}$ & $\mathbf{T}$ & $\mathbf{T}$ & $\mathbf{G}$ & $\mathbf{A}$ & G & $\mathbf{G}$ & $\mathbf{T}$ \\
\hline 9 & $\begin{array}{l}\text { RadhuniP } \\
\text { agal }\end{array}$ & G & G & $\mathbf{G}$ & $\mathbf{T}$ & $\mathbf{A}$ & $\mathbf{T}$ & C & $\mathbf{T}$ & C & & & $\mathbf{T}$ & & & & & & & & & & & & & & \\
\hline 10 & BR 2655 & G & $\mathbf{G}$ & $\mathbf{G}$ & $\mathbf{A}$ & $\mathbf{G}$ & $\mathbf{A}$ & $\mathbf{G}$ & $\mathbf{C}$ & G & $\mathbf{T}$ & $\mathbf{T}$ & $\mathbf{A}$ & $\mathbf{G}$ & $\mathrm{C}$ & & & & & & & & & & & & \\
\hline 11 & Karthika & $\mathbf{A}$ & $\mathbf{A}$ & $\mathbf{T}$ & G & & $\mathbf{T}$ & C & $\mathbf{T}$ & $\mathrm{C}$ & $\mathbf{T}$ & & $\mathbf{T}$ & $\mathbf{T}$ & & $\mathbf{G}$ & $\mathrm{C}$ & $\mathbf{T}$ & $\mathbf{G}$ & $\mathbf{A}$ & $\mathbf{T}$ & $\mathbf{T}$ & G & $\mathbf{A}$ & G & $\mathbf{G}$ & $\mathbf{T}$ \\
\hline 12 & Subhdra & & & G & $\mathbf{A}$ & $\mathbf{T}$ & & C & G & $\mathrm{C}$ & G & & $\mathbf{T}$ & $\mathbf{T}$ & $\mathbf{C}$ & & & & & $\mathbf{A}$ & & & & & & & \\
\hline 13 & $\begin{array}{l}\text { Morobere } \\
\text { kkan }\end{array}$ & $\mathbf{A}$ & $\mathbf{T}$ & $\mathbf{A}$ & $\mathbf{G}$ & & $\mathbf{T}$ & C & $\mathbf{T}$ & $\mathrm{C}$ & & & $\mathbf{T}$ & $\mathbf{T}$ & & $\mathbf{G}$ & $\mathrm{C}$ & $\mathbf{T}$ & $\mathbf{G}$ & $\mathbf{A}$ & $\mathbf{T}$ & $\mathbf{T}$ & $\mathrm{C}$ & $\mathbf{A}$ & $\mathbf{G}$ & $\mathbf{G}$ & $\mathbf{T}$ \\
\hline 14 & TKM 9 & C & G & G & G & & $\mathbf{T}$ & C & $\mathbf{T}$ & $\mathrm{C}$ & & & $\mathbf{T}$ & $\mathbf{T}$ & G & G & C & $\mathbf{T}$ & $\mathbf{G}$ & $\mathbf{A}$ & $\mathbf{T}$ & $\mathrm{C}$ & $\mathrm{C}$ & C & C & G & $\mathbf{T}$ \\
\hline
\end{tabular}

Table.8 Nucleotide variations observed in OsZIP 2-1

\begin{tabular}{|l|l|l|l|}
\hline Sl. No. & GENOTYPES & POSITIONS & $\mathbf{1 2}$ \\
\cline { 3 - 4 } & & $\mathbf{0 9}$ & $\mathbf{T}$ \\
\hline 1 & AM 27 & T & T \\
\hline 2 & AM 65 & C & T \\
\hline 3 & AM 72 & C & A \\
\hline 4 & AM 158 & T & A \\
\hline 5 & Black rice & A & C \\
\hline 6 & BI 33 & A & T \\
\hline 7 & AM 143 & A & C \\
\hline 8 & AM 1 & A & A \\
\hline 9 & RadhuniPagal & T & A \\
\hline 10 & BR-2655 & A & G \\
\hline 11 & Karthika & C & A \\
\hline 12 & Subhdra & A & A \\
\hline 13 & Moroberekkan & A & G \\
\hline 14 & TKM 9 & C & \\
\hline
\end{tabular}


Fig.1

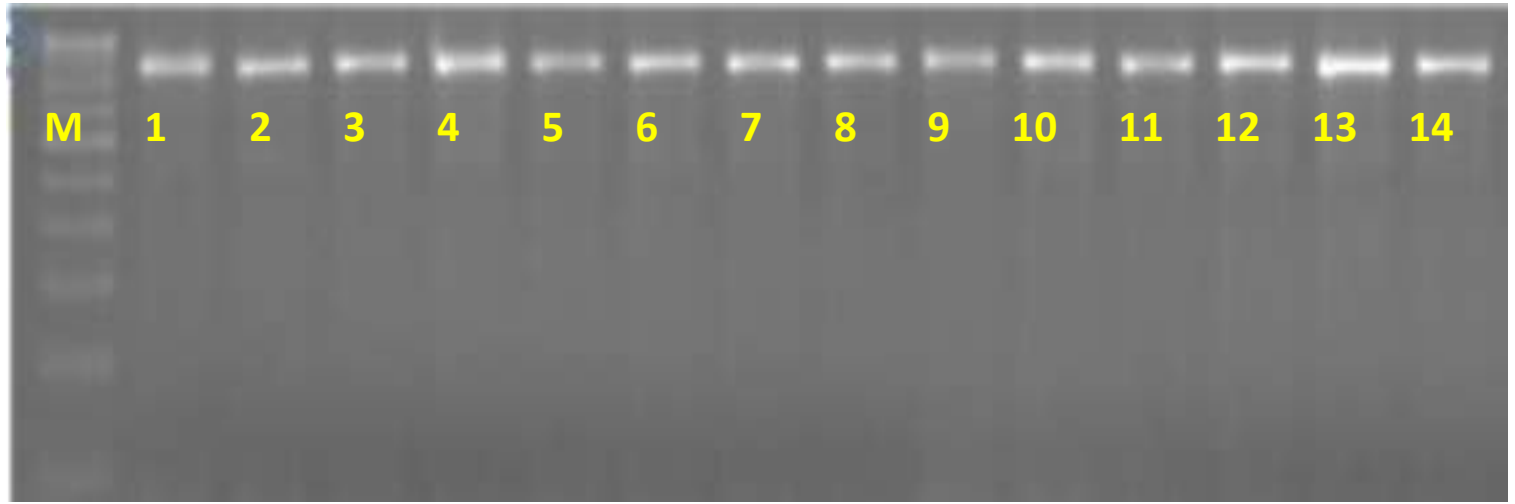

Agarose gel profile of OsZIP 2-3 $931 \mathrm{bp}$

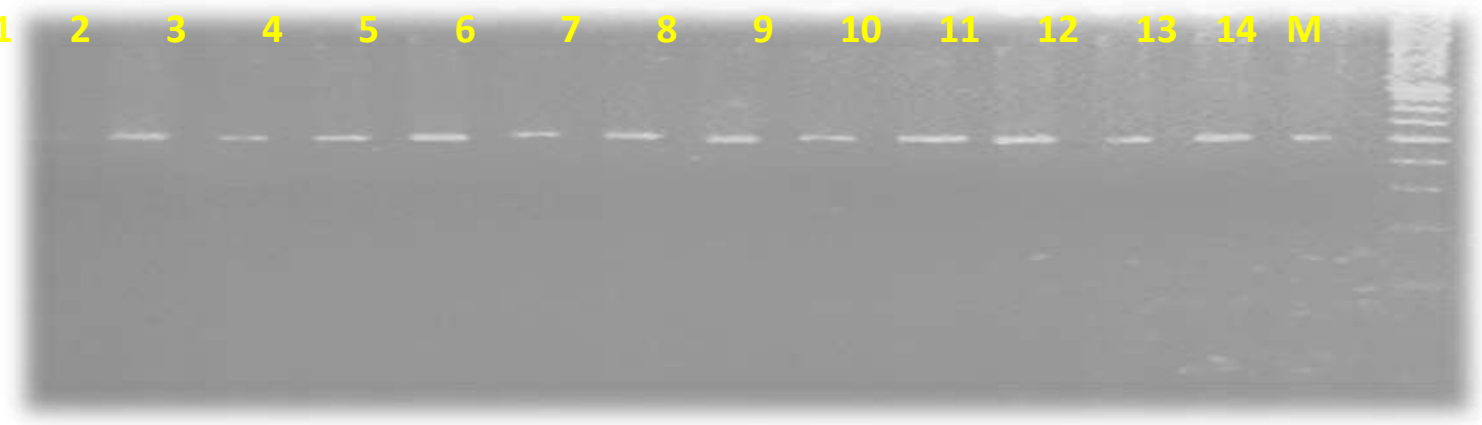

Agarose gel profile of OsZIP 7-2 602

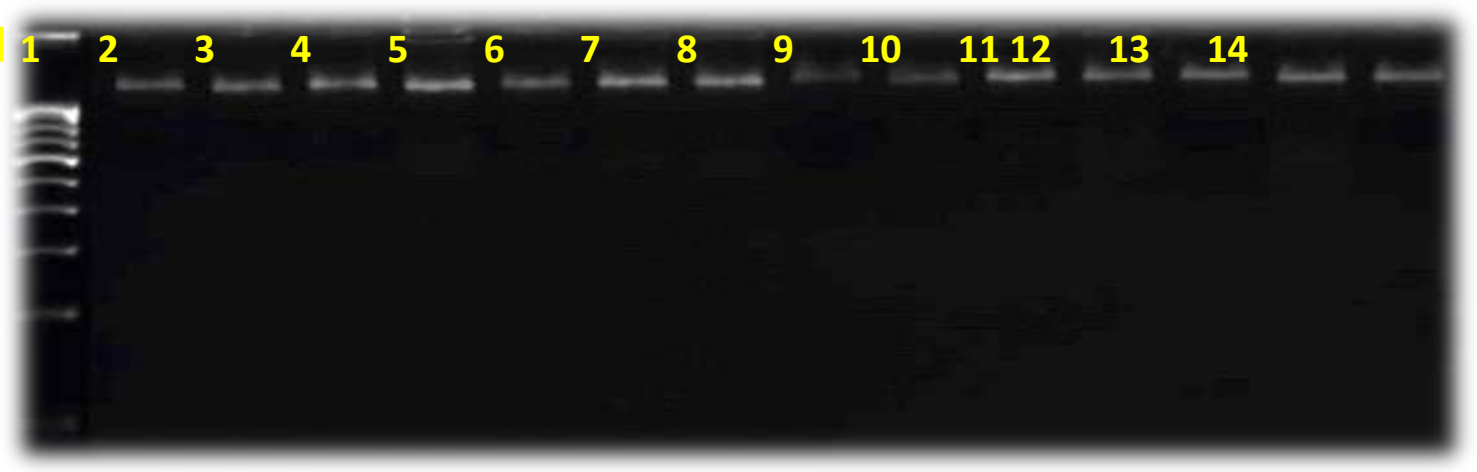

\section{Agarose gel profile of OsZIP 5-2 990 bp}

Amplicons of fourteen genotypes for eight primers were sequenced. Sequence of all the eight primers amplicons have given good quality read. The read length of the amplicons was varying but was on par with expected product size only. All the amplicons were found to have variations at nucleotide level which were less in OsZIP 2-1 (only two). Most of the sequence variation was found in OsZIP7-2 amplicon at nucleotide level. In case of OsZIP 2-1 there has been changes at 2 positions, at 9 position transversion from A to $\mathrm{T}$ were found for three genotypes, where transversion from A to $\mathrm{C}$ were found for four genotypes; at 12 position transition from A to $G$ for two genotypes, transversion from $A$ to $\mathrm{C}$ for two genotypes and transversion from $\mathrm{A}$ to $\mathrm{T}$ for four genotypes were found. In case of OsZIP 7-2, changes were noticed at 26 positions which were mostly deletions. At 
positions 464 and 542 deletions were found for T; deletions at 540 and 543 were found for $\mathrm{G} ; 544^{\text {th }}$ position for $\mathrm{A} ; 541^{\text {th }}$ position for C. Deletions as well as change in nucleotides to $\mathrm{T}$ could be seen at $34^{\text {th }}$ position from $\mathrm{A}$ and $\mathrm{G} ; 64^{\text {th }}$ position from $\mathrm{G} ; 516^{\text {th }}$ position from $\mathrm{G} ; 545^{\text {th }}$ position from $\mathrm{C} ; 553$ th position from $\mathrm{A}$ and $\mathrm{C}$. Changes were also found at 25th positions for $\mathrm{C}$ to $\mathrm{T}, \mathrm{G}$ and $\mathrm{A}$; at 26 for $\mathrm{G}$ to $\mathrm{T}$ and $A$; at 31th position for $G$ to $A$ and $T$. More changes were observed at 33rd position for $\mathrm{G}$ to $\mathrm{A}$ and $\mathrm{T}$; at 41th position for $\mathrm{C}$ to $\mathrm{A}$ and $\mathrm{G}$; at $48^{\text {th }}$ position for $\mathrm{C}$ to $\mathrm{G}$; at $488^{\text {th }}$ position from $\mathrm{T}$ to $\mathrm{C}$ and $\mathrm{A}$; at 534 from $\mathrm{G}$ to $\mathrm{C}$ with deletions for $\mathrm{G}$; at $548^{\text {th }}$ from $\mathrm{C}$ to $\mathrm{T}$ with deletions for $\mathrm{C}$ : at $549^{\text {th }}$ position from $\mathrm{C}$ to $\mathrm{G}$ with deletions for $\mathrm{C}$; at $550^{\text {th }}$ position from $\mathrm{A}$ to $\mathrm{G}$ and $\mathrm{C}$ With deletions for $\mathrm{A}$; at 551th position from $\mathrm{C}$ to $\mathrm{G}$ with deletions for $\mathrm{C}$; at 552th position from $\mathrm{G}$ to $\mathrm{C}$ with deletions for $\mathrm{G}$ were observed.

Both primers which manifested changes in nucleotides for the fourteen genotypes were selected. The analysis of scores in SPSS (Statistical Product and Service Solutions) package revealed the association of these sequence changes with the phenotypes. Results are summarized in Table 5and 6.OsZIP 2-1 showed association with only brown rice Zinc among the selected genotypes. It showed association with Zinc in brown rice at two nucleotide positions 09 and 12 with a phenotypic variance of $83.0 \%$ and $67.5 \%$ in all the respective nucleotide positions. OsZIP 7-2 showed association with Zinc content in brown rice at nucleotide position 25 with a phenotypic variance of $66.2 \%$, at nucleotide position 26 with a phenotypic variance of $62.7 \%$ and at nucleotide position 31 with a phenotypic variance of $69.7 \%$. OsZIP 7-2 showed association with Iron content in brown rice at 25, 33, 34, 40, 41, 43, 48, 64, 464, 516, 534, 540, 541, 542, 543, 544, 545, 548, 549, 550, 551, 552 and 553 position with Phenotyping variation of $70.6 \%, 43.8 \%, 60.8 \%, 62.0 \%$, $49.6 \%, 58.0 \%, 49.4 \%, 53.8 \%, 27.8 \%, 57.8$ $\%, 53.8 \%, 53.8 \%, 53.8 \%, 53.8 \%, 38.4 \%$, $58.6 \%, 55.3 \%, 53.8 \%, 54.3 \%, 62.0 \%, 55.8$ $\%$ and $56.2 \%$ respectively.

In conclusion, sequencing of the amplified products of two primers namely OsZIP2-1, OsZIP7-2, was done. All products manifested variation at the nucleotide level. Nucleotide changes in OsZIP7-2 had significant association with $\mathrm{Zn}$ content in brown rice and $\mathrm{Fe}$ content in brown rice. OsZIP2-1 showed association with only brown rice $\mathrm{Zn}$ among the selected genotypes. It showed association with brown rice zinc at two nucleotide positions. OsZIP7-2 showed association with Zinc content in brown rice at four nucleotide positions and it also showed association with brown rice zinc at 22 nucleotide positions. Ultimate objective was achieved by screening all the elite accessions with Grain Yield/Plant. It was found highest yield was for TKM-9. Karthika has been found to be high in Zinc and BR- 2655 for Iron in brown rice. Zinc loss after milling in white rice is only $3.48 \%$ in moroberekan suggesting the presence of efficient transporter from the aleurone layer to endosperm. It was also concluded that for iron content in brown rice further study of OsZIP7-2 is needed.

\section{References}

Ahmad, H. K., SWARAZ, A. M. AND JAMES, S., 2014, Zinc-deficiency resistance and biofortification in plants. J. Pl. Nutr. Soil Sci., Pp. 1-9.

Avendano, B. S., 2000, Tagging high zinc content in the grain, and zinc deficiency tolerance genes in rice (Oryza sativa L.) using simple sequence repeats (SSR). M. Sc. Thesis, Laguna College, Los Banos.

Baishya, L., Sarkar, D., Ansari, M. and Prakash, N., 2015, Yield, quality and 
profitability of rice (Oryza sativa L.) varieties grown in the eastern Himalayan region of India. Afr. $J$. Agric. Res., 10(11):1177-1183.

Banerjee, S. and Chandel, G., 2011, Understanding the role of metal homeostasis related candidate genes in $\mathrm{Fe} / \mathrm{Zn}$ uptake, transport and redistribution in rice using semiquantitative RT-PCR. J. Pl. Mol. Biol. Biotechnol., 2 (1): 33-46.

Bashir, K., Ishimaru, Y. and Nishizawa, N. K., 2012, Molecular mechanisms of zinc uptake and translocation in rice.Pl. Soil, 361 (1-2): 189-201.

Bekele, B, D., 2012, Identification and validation of molecular markers for zinc content in grains of rice (Oryza sativa L.) grown under aerobic condition. Ph.D Thesis, Univ. Agric. Sci., Bangalore.

Byrne, P. F. and Mcmullen, M. D., 1996, Defining genes for agricultural traits: QTL analysis and the candidate gene approach. Probe. 7: 24-27.

Chandel, G. P., Dubey S, M. and Meena R., 2011, In silico expression analysis of QTL specific candidate genes for grain micronutrient $(\mathrm{Fe} / \mathrm{Zn})$ content using ESTs and MPSS signature analysis in rice (Oryza sativa L.) J. Pl. Genet. Transgenics, 2(1): 11-22.

Doyle, J. J., and Doyle, J. L., 1990, Isolation of plant DNA from fresh tissue. Focus, 12: $13-15$.

Global Panel. 2015. Biofortification: An Agricultural Investment for Nutrition. Policy Brief No. 1. London, UK: Global Panel on Agriculture and Food Systems for Nutrition, pp. 2-6.

Harvest Plus, 2014, Kigali Declaration on Biofortified Nutritious Foods. Second Global Conference on Biofortification, Kigali, Rwanda.

Johnson, A. A. T., Kyriacou, B., Callahan, D. L., Carruthers, L., Stangoulis, J., 2011,
Constitutive overexpression of the OsNAS gene family reveals single-gene strategies for effective iron- and zincbiofortification of rice endosperm. PLoS One6 (9): e24476.

Larkin, M.A., Blackshields, G., Brown, N.P., Chenna, R., Mcgettigan, P.A., Mcwilliam, H., Valentin, F., Wallace, I.M., Wilm, A., Lopez, R., Thompson, J.D., Gibson, T.J. and Higgins, D.G., 2007, Clustal W and Clustal X version 2.0, Bioinfo, 23(21): 2947-2948.

Lee, S. and An, G., 2009, Over-expression of OsIRT1 leads to increased iron and zinc accumulations in rice. Pl. Cell Environ., 32: 408-416.

Lu, K., Li, L., Zheng, X., Zhang, Z., Mou, T., and $\mathrm{Hu}, \mathrm{Z}$., 2008, Quantitative trait loci controlling $\mathrm{Cu}, \mathrm{Ca}, \mathrm{Zn}, \mathrm{Mn}$ and $\mathrm{Fe}$ content in rice grains. J. Genet., 87 (3): $304-310$.

Lu, L., Tian, S., Lia, S., Zhang, J., Yang, X., Labavitch, J, M. and Chen, W., 2013, Analysis of Metal Element Distributions in Rice (Oryza sativa L.) Seeds and Relocation during Germination Based on X-Ray Fluorescence Imaging of $\mathrm{Zn}$, $\mathrm{Fe}, \mathrm{K}, \mathrm{Ca}$, and Mn. PLoS ONE, 8(2): 57360.

Pandey, S., Doss, D. and Shashidhar, H., 2018a, Evaluation of Elite Accessions of Rice for Morphological and Nutritional Traits. Int. J. Curr. Microbiol. App. Sci., 7(2): 3572-3580.

Pandey, S., Doss, D. and Shashidhar, H., 2018b, Correlation and path analysis of yield determinants and micronutrient content in rice (Oryza sativa L.). $J$. Pharmacogn. Phytochem. 7(1): 27232728.

Pandey, S., Doss, D. and Shashidhar, H., 2018c, Assessment of genetic variability, heritability and genetic advance for yield contributing and quality traits in rice (Oryza sativa L.) genotypes. J. Pharmacogn. 
Phytochem.7(4): 333-337.

Sellappan, K., Datta, K., Parkhi, V. and Datta, S. K., 2009, Rice caryopsis structure in relation to distribution of micronutrients (iron, zinc, carotene) of rice cultivars including transgenic indica rice. $\mathrm{Pl}$. Sci., 177: 557-562.

Sharma, A. and Chauhan, R. S., 2008, Identification of candidate gene-based markers (SNPs and SSRs) in the zinc and iron transporter sequences of maize (Zea mays L.). Curr. Sci., 95 (8):25.

Tuberosa, R. and Salvi, S., 2007, From QTLs to genes controlling root traits in maize: Scale and Complexity in Plant Systems Research. Gene-Plant-Crop Relations, 2: 15-24.
Waterhouse, A. M., Procter, J. B., Martin, D. M. A., Clamp, M. and Barton, G. J., 2009, Jalview version 2 - a multiple sequence alignment editor and analysis workbench, Bioinfo., 25(9): 1189-1191.

Ye, J., Coulouris, G., Zaretskaya, I., Cutcutache, I., Rozen, S. And Madden, T., 2012. Primer-Blast: A tool to design target-specific primers for polymerase chain reaction. Bmc Bioinfo., 13:134142.

Zhang, X., Zhang, G., Guo, L., Wang, H., Zeng, D., Dong, G., Qian, Q. and Xue, D., 2011, Identification of quantitative trait loci for $\mathrm{Cd}$ and $\mathrm{Zn}$ concentrations of brown rice grown in Cd-polluted soils. Euphytica, 180: 173-179.

\section{How to cite this article:}

Saurabh Pandey, D. Dayal Doss and Shashidhar, H.E. 2019. Identification of Candidate Gene based Markers (SNPs) in the ZIP Family Transporter Sequences of Rice (Oryza sativa L.). Int.J.Curr.Microbiol.App.Sci. 8(01): 2830-2842. doi: https://doi.org/10.20546/ijcmas.2019.801.297 